\title{
ORIGINAL ARTICLE PROGNOSTIC VALUE OF GRACE VERSUS TIMI SCORE FOR IN- HOSPITAL OUTCOMES AFTER NON-ST-ELEVATION ACUTE CORONARY SYNDROME
}

\author{
Dileep Kumar'1, Tahir Saghir ${ }^{1}$, Kamran Ahmed Khan ${ }^{1}$, Khalid Naseeb ${ }^{1}$, Gulzar Ali', \\ Mahfooz Ali ${ }^{1}$, Reeta Bai ${ }^{2}$, Rekha Kumari ${ }^{3}$, Hitesh Kumar ${ }^{3}$ \\ ${ }^{1}$ National Institute of Cardiovascular Diseases, Karachi, Pakistan, ${ }^{2}$ Dow University of Health Sciences Karachi, Pakistan, ${ }^{3}$ Medical \\ officer of Government of Sindh, Pakistan
}

\begin{abstract}
Objectives: To compare the predictive value of TIMI and GRACE score for predicting inhospital outcomes after non-ST elevation acute coronary syndrome (NSTE-ACS).

Methodology: This study included prospectively recruited cohort of patients presented to a tertiary care cardiac center of Karachi, Pakistan who were diagnosed with NSTE-ACS. GRACE and TIMI score were obtained and in-hospital mortality was recorded. The receiver operating characteristic (ROC) curves analysis was performed and area under the curve (AUC) was obtained as indicative of predictive value for both scores.

Results: A total of 300 patients were included, out of which 76.7\%(230) were male and mean age was $58.04 \pm 10.71$ years. Risk profile comprises of $84.3 \%(253)$ hypertensive, $42.0 \%(126)$ diabetic, $27.3 \%(82)$ smokers, $9.0 \%(27)$ obese, 15.3\%(46) dyslipidemic, and 31\%(93) with sedentary lifestyle. Mean GRACE and TIMI score were $120.19 \pm 33.17$ and $3.18 \pm 0.85$ respectively. In-hospital mortality rate was $5.3 \%(16)$. AUC for the GRACE score was 0.851 [0.767 - 0.934] with the optimal cut-off value of 150 with sensitivity of $68.8 \%$ and specificity of $84.9 \%$. The AUC for the TIMI score was 0.781[0.671 - 0.891] with the optimal cut-off value of 4 with sensitivity of $75.0 \%$ and specificity of $67.6 \%$.

Conclusion: The GRACE score has high discriminating strength for predicting in-hospital mortality after NSTE-ACS. GRACE score should be used as risk stratification modality in clinical decision making for the management of NSTE-ACS.
\end{abstract}

Keywords: prognostic value, GRACE, TIMI, NSTE-ACS, mortality

Citation: Kumar D, Saghir T, Khan KA, Naseeb K, Ali G, Ali M, Bai R, Kumari R, Kumar H. Prognostic value of GRACE versus TIMI Score for In-hospital Outcomes after Non-ST-Elevation Acute Coronary Syndrome. Pak Heart J. 2021;54(04):361-366.

\section{INTRODUCTION}

Acute coronary syndrome (ACS) is a clinical condition that results from reduced coronary blood flow leading to improper function of the heart muscle. The ACS is comprised of ST-segment elevation myocardial infarction (STEMI), non-ST-segment elevation myocardial infarction (NSTEMI) and Unstable Angina. Furthermore, these conditions have been the significant reasons of worldwide morbidity and mortality. Its results are practically comparable in most of the cases regardless of their social background ethnicity, and race. ${ }^{1}$ Proper management of several modifiable risk factors including, hypertension, diabetes, smoking, obesity, and sedentary life style is highly valuable for primary prevention of coronary artery disease. ${ }^{2}$ Moreover, there are various tools and risk stratification modalities are available for the assessment of severity of coronary artery ischemia, which resulted from acute coronary syndrome. ${ }^{3,4}$ These modalities are useful for clinicians in risk stratification and subsequent management of the patients. $^{5}$
Individualized risk stratification for maximal treatment of patients with ACS will be helpful to stratify further in to high risk groups who are most likely to get benefit from the intervention and in to low risk groups in which medical treatment would be most beneficial. These patients should be risk stratified at the time of admission to decide for further management strategies. Thrombolysis in myocardial infarction (TIMI) risk score or global registry of acute coronary events (GRACE) risk score are considered superior to the available risk scores because of their easiness and high accuracy. ${ }^{6-7}$ In some studies GRACE score demonstrated its superiority in the assessment of 6-months mortality risk but still conspicuous. ${ }^{8,9}$

Therefore, the rationale of the study was to compare the performance, in terms of prognostic value, of GRACE and TIMI score in determining the in-hospital outcomes after non-ST-elevation acute coronary syndrome (NSTE-ACS). So the better of the two could be utilized in subsequent patients thereby prognosis may be improved. 


\section{METHODOLOGY}

This prospective study was conducted at the National Institute of Cardiovascular Disease (NICVD), Karachi, Pakistan during October 2019 to March 2020. Ethical review committee (ERC) approval was obtained from the institution ERC (ERC-43/2019) and verbal informed consent regarding participation in the study was obtained from all the patients. Patients of either gender, age ranging from 18 to 80 years, and diagnosed with NSTE-ACS were included consecutively. Patients with prior history of any cardiac related surgery or intervention or refused to give consent were excluded from the study.

In accordance with clinical practice guidelines of the American College of Cardiology (ACC), NSTE-ACS was defined in patients presented with typical chest pain for more than 20 minutes, presentation electrocardiogram (ECG) findings of transient ST elevation, ST depression, or/and T-wave inversions, and typical rise of cardiac enzymes. Demographic clinical details, such as gender, age(years), height $(\mathrm{cm})$, and weight $(\mathrm{kg})$, and baseline risk profile of the patients were obtained which included hypertension (on antihypertensive medication for $\geq 6$ months), diabetes (on hyperglycemic treatment for $\geq 6$ months), dyslipidemia (based on lipid profile), smoking ( $\geq 10$ cigarettes per day for at least one year), obesity (body mass index > $27.5 \mathrm{~kg} / \mathrm{m} 2$ ), history of premature coronary artery diseases in first degree relatives (male under 55 years and female under 65 years of age), and sedentary lifestyle. Baseline GRACE score was calculated based demographic and clinical parameters, such as blood pressure (systolic), age (years), Killip class and cardiac arrest at presentation, heart rate, baseline electrocardiograph (ECG) evidence of STsegment deviation, basal serum creatinine, and initial cardiac biomarker using calculator available at https://www.mdcalc.com/grace-acs-risk-mortalitycalculator. Baseline TIMI score for unstable angina / NSTE-ACS was calculated as per the layout put forth by Antman EM et al. ${ }^{10}$

All the patients were managed by the consultant cardiology as per the ACC management guidelines for NSTE-ACS and institutions protocols. ${ }^{11}$ All the enrolled patients were kept under observation during their hospital stay and in-hospital outcomes were observed, which included heart failure (HF), remyocardial infarction (MI), ventricular tachycardia (VT), atrial fibrillation (Afib), cardiogenic shock (CS), heart block, and in-hospital mortality.
The minimum required sample size of $n=237$ patients was computed at $95 \%$ confidence level, $5 \%$ margin of error, and with 0.62 of expected area under the curve (AUC), ${ }^{6}$ and in account for the design effect a total of 300 patients were recruited for this study. Statistical analysis were performed using IBM SPSS (version 21 ), collected data were expressed with appropriate summary statistics such as frequency percentages or mean \pm standard deviation (SD). AUC and its asymptotic $95 \%$ confidence interval were reported for the receiver operating characteristic (ROC) curve analysis as a predictive value of GRACE and TIMI score. Patients were categorized in to two groups based on GRACE score at optimal cutoff value of 150 computed using the ROC curves analysis. The profile and outcome differences between the high and low risk group of patients were compared by performing appropriate Chi-square test or Student's t test/MannWhitney U test. Adjusted and unadjusted odds ratios (OR) along with its $95 \%$ confidence intervals were reported for the univariate and multivariate binary logistic regression analysis respectively. In-hospital mortality as taken as regress and clinical and demographic factors were taken as regressors. A pvalue $\leq 0.05$ was taken as significance criteria in all analysis.

\section{RESULTS}

In this study we included 300 patients, out of which $76.7 \%$ (230) were male and mean age was $58.04 \pm$ 10.71 years with more than $20 \%$ above 65 years of age. Risk profile comprises of $84.3 \%$ (253) hypertensive, $42.0 \%$ (126) diabetic, $27.3 \%$ (82) smokers, $9.0 \%$ (27) obese, $15.3 \%$ (46) dyslipidemic, and 31\% (93) with sedentary lifestyle. Mean GRACE and TIMI score were $120.19 \pm 33.17$ and $3.18 \pm 0.85$ respectively. Demographic and clinical characteristics of the enrolled patients stratified by GRACE score are presented in Table 1 .

Table 1: Characteristics of the patients stratified by GRACE score

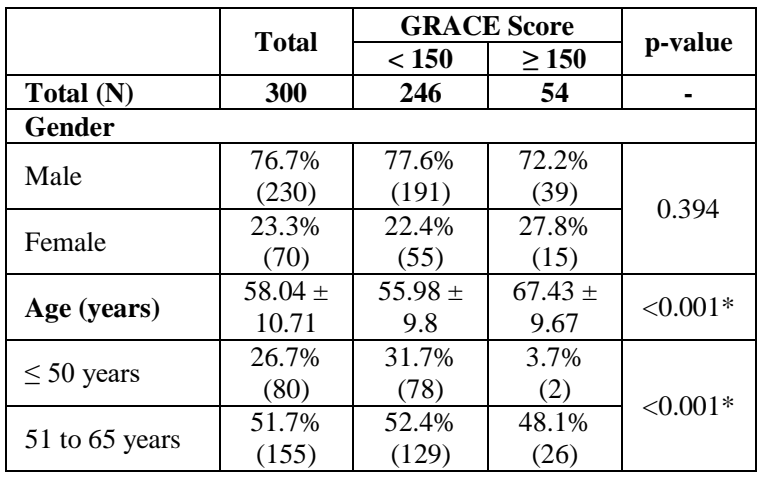




\begin{tabular}{|c|c|c|c|c|}
\hline$>65$ years & $\begin{array}{c}21.7 \% \\
(65) \\
\end{array}$ & $\begin{array}{c}15.9 \% \\
(39) \\
\end{array}$ & $\begin{array}{c}48.1 \% \\
(26) \\
\end{array}$ & \\
\hline \multicolumn{5}{|l|}{ Risk factors } \\
\hline Hypertension & $\begin{array}{l}84.3 \% \\
(253)\end{array}$ & $\begin{array}{l}85 \% \\
(209)\end{array}$ & $\begin{array}{c}81.5 \% \\
(44)\end{array}$ & 0.524 \\
\hline Diabetes & $\begin{array}{l}42 \% \\
(126) \\
\end{array}$ & $\begin{array}{c}39.8 \% \\
(98) \\
\end{array}$ & $\begin{array}{c}51.9 \% \\
(28)\end{array}$ & 0.105 \\
\hline $\begin{array}{l}\text { Family history } \\
\text { of CAD }\end{array}$ & $\begin{array}{l}11 \% \\
(33)\end{array}$ & $\begin{array}{l}11 \% \\
(27)\end{array}$ & $\begin{array}{c}11.1 \% \\
(6)\end{array}$ & 0.977 \\
\hline Smoking & $\begin{array}{c}27.3 \% \\
(82)\end{array}$ & $\begin{array}{c}25.6 \% \\
(63)\end{array}$ & $\begin{array}{c}35.2 \% \\
(19)\end{array}$ & 0.153 \\
\hline Obesity & $9 \%(27)$ & $\begin{array}{c}10.6 \% \\
(26)\end{array}$ & $\begin{array}{c}1.9 \% \\
(1)\end{array}$ & $0.043 *$ \\
\hline Dyslipidemia & $\begin{array}{c}15.3 \% \\
(46)\end{array}$ & $\begin{array}{c}17.1 \% \\
(42)\end{array}$ & $\begin{array}{c}7.4 \% \\
(4)\end{array}$ & 0.074 \\
\hline $\begin{array}{l}\text { Sedentary } \\
\text { lifestyle }\end{array}$ & $\begin{array}{l}31 \% \\
(93)\end{array}$ & $\begin{array}{c}32.9 \% \\
(81)\end{array}$ & $\begin{array}{c}22.2 \% \\
(12)\end{array}$ & 0.124 \\
\hline \multicolumn{5}{|l|}{ KILLIP Class } \\
\hline I & $\begin{array}{l}84.3 \% \\
(253)\end{array}$ & $\begin{array}{l}89.8 \% \\
(221)\end{array}$ & $\begin{array}{l}59.3 \% \\
(32)\end{array}$ & \multirow{4}{*}{$<0.001 *$} \\
\hline II & $\begin{array}{l}13 \% \\
(39) \\
\end{array}$ & $\begin{array}{l}8.9 \% \\
(22) \\
\end{array}$ & $\begin{array}{c}31.5 \% \\
(17)\end{array}$ & \\
\hline III & $2 \%(6)$ & $0.8 \%(2)$ & $\begin{array}{l}7.4 \% \\
(4)\end{array}$ & \\
\hline IV & $\begin{array}{c}0.7 \% \\
(2)\end{array}$ & $0.4 \%(1)$ & $\begin{array}{c}1.9 \% \\
(1)\end{array}$ & \\
\hline Cardiac arrest & $\begin{array}{c}3.7 \% \\
(11)\end{array}$ & $1.6 \%(4)$ & $13 \%(7)$ & $<0.001 *$ \\
\hline $\begin{array}{l}\text { Heart Rate } \\
\text { (bpm) }\end{array}$ & $\begin{array}{c}77.43 \pm \\
14.29\end{array}$ & $\begin{array}{c}75.31 \pm \\
12.58\end{array}$ & $\begin{array}{c}87.07 \pm \\
17.49\end{array}$ & $<0.001 *$ \\
\hline $\begin{array}{l}\text { Systolic blood } \\
\text { pressure } \\
(\mathrm{mmHg})\end{array}$ & $\begin{array}{r}120.99 \\
\pm 17.21\end{array}$ & $\begin{array}{c}120.82 \\
\pm 17.69\end{array}$ & $\begin{array}{c}121.78 \\
\pm 14.98\end{array}$ & 0.711 \\
\hline $\begin{array}{l}\text { Serum } \\
\text { creatinine } \\
(\mathrm{ng} / \mathrm{dL})\end{array}$ & $\begin{array}{l}1.45 \pm \\
6.75\end{array}$ & $\begin{array}{l}1.53 \pm \\
7.48\end{array}$ & $\begin{array}{l}1.13 \pm \\
0.52\end{array}$ & 0.7 \\
\hline $\begin{array}{l}\text { Troponin I } \\
\text { (ng/dL) }\end{array}$ & $\begin{array}{l}7.12 \pm \\
17.05\end{array}$ & $\begin{array}{l}7.09 \pm \\
18.44\end{array}$ & $\begin{array}{l}7.23 \pm \\
8.35\end{array}$ & 0.956 \\
\hline \multicolumn{5}{|l|}{ Risk Scores } \\
\hline GRACE Score & $\begin{array}{r}120.19 \\
\pm 33.17\end{array}$ & $\begin{array}{c}108.8 \pm \\
23.4\end{array}$ & $\begin{array}{c}172.07 \\
\pm 18.26\end{array}$ & $<0.001 *$ \\
\hline TIMI Score & $\begin{array}{l}3.18 \pm \\
0.85\end{array}$ & $\begin{array}{c}3.16 \pm \\
0.81\end{array}$ & $\begin{array}{c}3.26 \pm \\
1.03\end{array}$ & 0.433 \\
\hline
\end{tabular}

$C A D=$ coronary artery diseases, GRACE $=$ Global Registry for Acute Coronary Events, TIMI = thrombolysis in myocardial infarction

*significant at 5\%

In-hospital mortality rate was 5.3\% (16) and among other in-hospital outcomes heart failure was observed in $11 \%$ (33), LBBB/RBBB in $4.0 \%$ (12), Cardiogenic Shock in $3.7 \%$ (11), and atrial fibrillation in $2.3 \%$ (7) of the patients. In-hospital outcomes stratified by GRACE score are presented in Table 2. The AUC for the GRACE score was 0.851 [0.767 - 0.934] with the optimal cutoff value of 150 with sensitivity of $68.8 \%$ and specificity of $84.9 \%$. The AUC for the TIMI score was $0.781[0.671-0.891]$ which comparatively smaller than that of GRACE score, representing higher predictive value GRACE score as compared to TIMI score. The optimal cutoff value for TIMI score was calculated to be 4 with sensitivity of $75.0 \%$ and specificity of $67.6 \%$. The ROC curves of GRACE and
TIMI score for in-hospital mortality are presented in Figure 1.

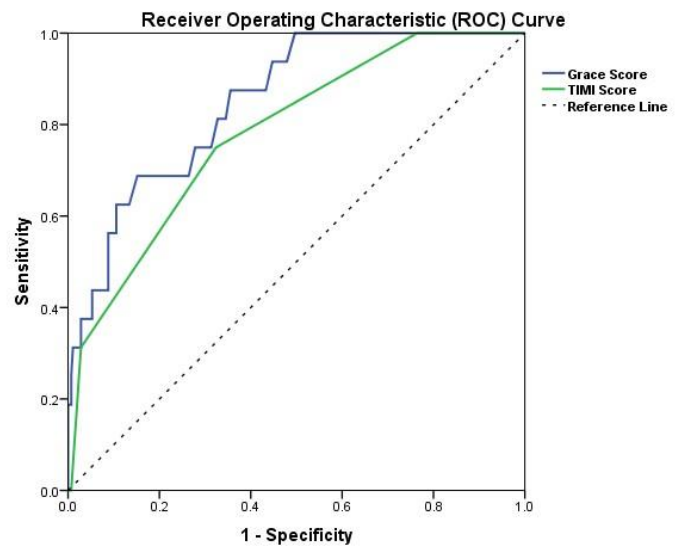

Figure 1: Comparison of ROC analysis of GRACE and TIMI score for in-hospital mortality

GRACE score of $\geq 150$ was found to be associated with a significant increase in mortality rate, $20.4 \%$ $(11 / 54)$ vs. $2.0 \%(5 / 246) ; \mathrm{p}<0.001$, with higher relative risk of 12.33 [4.08-37.26]. Similarly, rates of other adverse outcomes, such as heart failure, ventricular tachycardia, atrial fibrillation, and cardiogenic shock, were also significantly higher in patient groups with GRACE score of $\geq 150$, as shown in Table 2 .

Table 2: In-hospital outcomes stratified by GRACE score

\begin{tabular}{|c|c|c|c|c|}
\hline \multirow{2}{*}{ Characteristics } & \multirow{2}{*}{ Total } & \multicolumn{2}{|c|}{ GRACE Score } & \multirow{2}{*}{ P-value } \\
\hline & & $<150$ & $\geq 150$ & \\
\hline Total $(\mathbf{N})$ & 300 & 246 & 54 & - \\
\hline \multicolumn{5}{|c|}{ In-hospital Outcomes } \\
\hline Heart Failure & $\begin{array}{l}11 \% \\
(33)\end{array}$ & $\begin{array}{l}5.3 \% \\
(13) \\
\end{array}$ & $37 \%(20)$ & $<0.001 *$ \\
\hline $\begin{array}{l}\text { Re-myocardial } \\
\text { infarction }\end{array}$ & $0 \%(0)$ & $0 \%(0)$ & $0 \%(0)$ & - \\
\hline $\begin{array}{l}\text { Ventricular } \\
\text { tachycardia }\end{array}$ & $\begin{array}{l}0.7 \% \\
(2)\end{array}$ & $0 \%(0)$ & $3.7 \%(2)$ & $0.002^{*}$ \\
\hline $\begin{array}{l}\text { Atrial } \\
\text { fibrillation }\end{array}$ & $\begin{array}{l}2.3 \% \\
(7)\end{array}$ & $\begin{array}{l}0.8 \% \\
(2)\end{array}$ & $9.3 \%(5)$ & $<0.001 *$ \\
\hline $\begin{array}{l}\text { Cardiogenic } \\
\text { Shock }\end{array}$ & $\begin{array}{l}3.7 \% \\
(11)\end{array}$ & $\begin{array}{l}1.2 \% \\
(3)\end{array}$ & $\begin{array}{c}14.8 \% \\
(8)\end{array}$ & $<0.001^{*}$ \\
\hline Heart block & $\begin{array}{l}0.7 \% \\
(2)\end{array}$ & $\begin{array}{l}0.8 \% \\
(2)\end{array}$ & $0 \%(0)$ & 0.506 \\
\hline LBBB / RBBB & $\begin{array}{l}4 \% \\
(12)\end{array}$ & $\begin{array}{l}3.3 \% \\
(8)\end{array}$ & $7.4 \%(4)$ & 0.158 \\
\hline Mortality & $\begin{array}{l}5.3 \% \\
(16)\end{array}$ & $2 \%(5)$ & $\begin{array}{c}20.4 \% \\
(11)\end{array}$ & $<0.001 *$ \\
\hline
\end{tabular}

In univariate analysis, both GRACE score of $\geq 150$ and TIMI score of $\geq 4$ were found to be associated with increased risk of mortality with unadjusted OR of 12.33 [4.08-37.26] and 6.26 [1.97-19.94] respectively. 
Among other clinical characteristics, cardiac arrest (OR: 471.7 [51.8-4295.0]), KILLIP class II-IV (OR: 42.58 [9.01-201.19]), and diabetes (OR: 4.47 [1.4114.22]) were also found to have significant association with increased mortality rate. Even after adjusting for all the significant factors, risk of mortality among patients with GRACE score of $\geq 150$ was found to be significantly higher with adjusted OR of 18.1 [2.31141.93] validating the discriminating power of GRACE score. The univariate and multivariate binary logistic regression analysis for in-hospital mortality are presented in Table 3.

Table 3: Univariate and multivariate logistic regression analysis for in-hospital mortality

\begin{tabular}{|l|c|c|c|c|}
\hline \multirow{2}{*}{ Parameters } & \multicolumn{2}{|c|}{ Bivariate Analysis } & \multicolumn{2}{c|}{ Multivariate Analysis } \\
\cline { 2 - 5 } & OR [95\% CI] & P & OR [95\% CI] & P \\
\hline Female & $2.06[0.72-5.89]$ & 0.176 & - & - \\
\hline Age > 65 years & $2.59[0.94-7.15]$ & 0.065 & $0.85[0.13-5.46]$ & 0.863 \\
\hline Heart Rate (per 5 bpm) & $1.19[1.03-1.37]$ & $0.017 *$ & $0.84[0.58-1.21]$ & 0.341 \\
\hline Creatinine (ng/dL) & $1[0.94-1.07]$ & 0.954 & - & - \\
\hline Troponin I (ng/dL) & $1[0.99-1.02]$ & 0.624 & - & - \\
\hline Cardiac arrest & $471.7[51.8-4295.0]$ & $<0.001^{*}$ & $235.94[14.22-3915.63]$ & $<0.001^{*}$ \\
\hline KILLIP class II-IV & $42.58[9.01-201.19]$ & $<0.001^{*}$ & $3.89[0.08-187.75]$ & 0.492 \\
\hline Hypertension & $2.9[0.37-22.49]$ & 0.309 & - & - \\
\hline Diabetes & $4.47[1.41-14.22]$ & $0.011^{*}$ & $2.3[0.4-13.32]$ & 0.354 \\
\hline FHx CAD & $1.95[0.53-7.25]$ & 0.317 & - & - \\
\hline Smoking & $0.88[0.28-2.81]$ & 0.83 & - & - \\
\hline Obesity & $1.51[0.19-11.91]$ & 0.695 & - & - \\
\hline Dyslipidemia & $1.28[0.28-5.84]$ & 0.747 & - & - \\
\hline Sedentary lifestyle & $1.01[0.34-3]$ & 0.982 & - & - \\
\hline GRACE Score $\geq 150$ & $12.33[4.08-37.26]$ & $<0.001^{*}$ & $18.1[2.31-141.93]$ & $0.006^{*}$ \\
\hline TIMI Score $\geq 4$ & $6.26[1.97-19.94]$ & $0.002^{*}$ & $2.29[0.41-12.69]$ & 0.345 \\
\hline
\end{tabular}

FHx CAD = family history of coronary artery diseases, GRACE = Global Registry for Acute Coronary Events, TIMI = thrombolysis in myocardial infarction, $O R=$ odds ratio, $C I=$ confidence interval

*significant at $5 \%$

\section{DISCUSSION}

In our study, we compared the prognostic strength of GRACE versus TIMI score for in-hospital outcomes after NSTE-ACS. This study shows that risk scores, both GRACE and TIMI, were higher in patients with risk factors of coronary artery disease (CAD) and the complications were presumably seen in these patients including a high mortality. However the GRACE risk score was found to be more effective prognostic marker than the TIMI risk score. The AUC for the GRACE score was found to be 0.851 as against 0.781 for TIMI score, representing higher discriminating strength of GRACE score as compared to the TIMI score.

The utility of GRACE score as prognostic marker in NSTE-ACS patients has been tested in various clinical settings, alone as well as in comparison to the other risk scores such as TIMI score, and in most of these attempts GRACE score standout with higher discriminating power. ${ }^{12-13}$ A study by Shaikh MK et al. ${ }^{14}$ reported validation of GRACE score for NSTEACS patients with 0.803 AUC and increasing inhospital mortality rate of $0.7 \%, 1.7 \%$, and $8.4 \%$ at the GRACE score of $\leq 108$ (low risk), between 109 to 140 (intermediate risk), and $>140$ (high risk) respectively. It has been also validated in various sub-groups of the population, for example, Gong IY et al. ${ }^{15}$ reported good calibration of GRACE score for both male and female NSTE-ACS patients with AUC of 0.85 and 0.82 respectively. Similarly, Meune C et al. ${ }^{16}$ reported accuracy of GRACE score in discriminating both inhospital and one-year mortality for the complete ACS spectrum, STEMI and NSTE-ACS, with AUC of 0.87 and 0.88 respectively.

Aragam KG and colleagues argued whether simplicity of the risk score compromises its accuracy and compared GRACE score with TIMI score, a relatively simpler score, in overall ACS spectrum and also for NSTE-ACS sub-group separately. The GRACE score outperformed TIMI score in predicting in-hospital as well as post discharge 6-months outcome not only for the NSTE-ACS sub-group but also for the complete ACS spectrum, hence, supporting their argument that the simplicity of the TIMI score due to omission of key factors does compromised its predictive accuracy. ${ }^{17}$ In a study by Ramsay $\mathrm{G}$ et al. ${ }^{13}$ the GRACE risk score was more prevalent then the TIMI score for determining major cardiac adverse events $(z=2.05)$, and both scores were more useful than the clinical evaluation with AUC of 0.82, 0.74 and 0.55 for GRACE, TIMI, and clinical assessment respectively. It has been also found to be superior to the TIMI score for predicting 30-day mortality and one-year mortality in patients with NSTE-ACS. ${ }^{5,18}$ The superiority of the GRACE score over TIMI score was also formally apprised by D'Ascenzo F et al. ${ }^{6}$ in a meta-analysis of 
42 validation and 40 derivation studies collectively comprised of 248,177 ACS patients.

In our study, the optimal cutoff of 150 for GRACE score has sensitivity of $68.8 \%$ and specificity of $84.9 \%$, similarly, the sensitivity and specificity of TIMI score at optimal cutoff of 4 are $75.0 \%$ and $67.6 \%$ respectively. Subsequently, rates of other adverse outcomes, such as heart failure, ventricular tachycardia, atrial fibrillation, and cardiogenic shock, were also significantly higher in patient groups with GRACE score of $\geq 150$. Among other clinical characteristics, cardiac arrest (OR: 471.7 [51.84295.0]), KILLIP class II-IV (OR: 42.58 [9.01201.19]), and diabetes (OR: 4.47 [1.41-14.22]) were found to have significant association with increased mortality rate.

GRACE risk score includes a multiple of clinical, laboratory, and electrocardiographic parameters. Although, some of the parameters of TIMI score like risk factors, prior coronary artery disease $(>50 \%)$, previous aspirin use and complaining of angina within 24 hours are characteristic of extensive coronary artery disease and which are not including in GRACE score, but, due to lack of other potentially discriminating variables such as the heart rate, heart failure, blood pressure, renal function and cardiac arrest at presentation are not included in the TIMI score for NSTE-ACS resulting in its poor discriminating strength.

\section{CONCLUSION}

In conclusion, both TIMI and GRACE score are useful modalities for discriminating NSTE-ACS patients at increased risk of in-hospital mortality, however, prognostic strength of GRACE score was found to be superior to that of TIMI score. Furthermore, GRACE score is and independent predictor of mortality and an optimal cut-off value of 150 provides a good specificity and a reasonable sensitivity. Hence, it can be a useful clinical support modality to rule in high risk NSTE-ACS patients and their subsequent decision making and management plan.

\section{AUTHORS' CONTRIBUTION}

DK, and TS: Concept and design, data acquisition, interpretation, drafting, final approval, and agree to be accountable for all aspects of the work. KAK, KN, GA, MA, RB, RK, and HK: Data acquisition, interpretation, drafting, final approval and agree to be accountable for all aspects of the work.

Conflict of interest: Authors declared no conflict of interest.

\section{REFERENCES}

1. Bowry AD, Lewey J, Dugani SB, Choudhry NK. The burden of cardiovascular disease in low-and middle-income countries: epidemiology and management. Can J Cardiol. 2015;31(9):11519.

2. Alnasser SM, Huang W, Gore JM. Late consequences of acute coronary syndromes: Global registry of acute coronary events (GRACE) follow-up. Am J Med. 2015;128:766-75.

3. Amsterdam EA, Wenger NK, Brindis RG. AHA/ACC guideline for the management of patients with non-ST-elevation acute coronary syndromes: executive summary, a report of the American College of Cardiology/American Heart Association Task Force on Practice Guidelines. J Am Coll Cardiol. 2014:64;2645-87.

4. Kozieradzka A, Kamiński KA, Maciorkowska D, Olszewska M, Dobrzycki S, Nowak K, et al. GRACE, TIMI, Zwolle and CADILLAC risk scores-Do they predict 5-year outcomes after ST-elevation myocardial infarction treated invasively?.Int $\mathrm{J}$ Cardiol. 2011;148:70-5.

5. de Araújo Gonçalves P, Ferreira J, Aguiar C, Seabra-Gomes R. TIMI, PURSUIT, and GRACE risk scores: sustained prognostic value and interaction with revascularization in NSTE-ACS. Eur Heart J. 2005;26(9):865-72.

6. Ascenzo FD, Biondi-Z G, Moretti C, Bollati M, Omedè P. TIMI, GRACE and alternative risk scores in acute coronary syndromes: a meta-analysis of 40 derivation studies on 216,552 patients and of 42 validation studies on 31,625 patients. Contemp Clin Trials. 2012;33:507-14.

7. Goodman SG, Huang W, Yan AT, Budaj A, Kennelly BM, Gore JM, et al. The expanded Global Registry of Acute Coronary Events: baseline characteristics, management practices, and hospital outcomes of patients with acute coronary syndromes. Am Heart J. 2009;158(2):193-201.

8. Cannon CP, Weintraub WS, Demopoulos LA, Robertson DH, Gormley GJ, Braunwald E. Invasive versus conservative strategies in instable angina and non-Q-wave myocardial infarction following treatment with tirofiban: rationale and study design of the International TACTICS-TIMI 18 trial. Am J Cardiol. 1998;82:731-6.

9. Granger CB, Goldberg RJ, Dabbous O, Pieper KS, Eagle KA, Cannon CP, et al. Predictors of hospital mortality in the Global Registry of Acute Coronary Events. Arch Intern Med. 2003; 163:2345-53.

10. Antman EM, Cohen M, Bernink PJ, McCabe CH, Horacek T, Papuchis G, et al. The TIMI risk score for unstable angina/non-ST elevation MI: a method for prognostication and therapeutic decision making. JAMA. 2000;284(7):835-42.

11. Amsterdam EA, Wenger NK, Brindis RG, Casey DE, Ganiats TG, Holmes DR, et al. 2014 AHA/ACC guideline for the management of patients with non-ST-elevation acute coronary syndromes: a report of the American College of Cardiology/American Heart Association Task Force on Practice Guidelines. J Am Coll Cardiol. 2014;64(24):e139-228.

12. Luo JG, Yang M, Han L, Jia X, Chen LW, Zhao Y. Validity of the GRACE score for 6-month death or reinfarction after presentation with acute myocardial infarction in patients 80 years of age and older. Coron Artery Dis. 2013;24(7):537-41.

13. Ramsay G, Podogrodzka M, McClure C, Fox KA. Risk prediction in patients presenting with suspected cardiac pain: the GRACE and TIMI risk scores versus clinical evaluation. QJM. 2007;100(1):11-8.

14. Shaikh MK, Hanif B, Shaikh K, Khan W, Parkash J. Validation of grace risk score in predicting in-hospital mortality in patients with non ST-elevation myocardial infarction and unstable angina. JPMA. 2014;64(7):807-11.

15. Gong IY, Goodman SG, Brieger D, Gale CP, Chew DP, Welsh $\mathrm{RC}$, et al. GRACE risk score: Sex-based validity of in-hospital mortality prediction in Canadian patients with acute coronary syndrome. Int J Cardiol. 2017;244:24-9. 
16. Meune C, Drexler B, Haaf P, Reichlin T, Reiter M, Meissner J, et al. The GRACE score's performance in predicting in-hospital and 1-year outcome in the era of high-sensitivity cardiac troponin assays and B-type natriuretic peptide. Heart. 2011;97(18):147983.

17. Aragam KG, Tamhane UU, Kline-Rogers E, Li J, Fox KA, Goodman SG, et al. Does simplicity compromise accuracy in ACS risk prediction? A retrospective analysis of the TIMI and GRACE risk scores. PloS One. 2009;4(11):e7947.

18. Schellings DA, Adiyaman A, Dambrink JH, Gosselink AM, Kedhi E, Roolvink V, et al. Predictive value of NT-proBNP for 30-day mortality in patients with non-ST-elevation acute coronary syndromes: a comparison with the GRACE and TIMI risk scores. Vasc Health Risk Manag. 2016;12:471-6.

\section{Address for Correspondence:}

Dr. Dileep Kumar, Post fellow at National Institute of Cardiovascular Diseases (NICVD), Karachi, Pakistan.

Email: dileep_dewani2011@yahoo.com 